\title{
Treatment of Dysmenorrhea with Physiological Modulators (A28): A Registry Study
}

\author{
Belcaro G, ${ }^{1}$ Cornelli U, ${ }^{2 *}$ Hernández Santos JR ${ }^{3}$ \\ ${ }^{1}$ University G.d' Annunzio Chieti, Pescara, Italy \\ ${ }^{2}$ Loyola University School of Medicine, USA \\ ${ }^{3}$ Centro MèdicoNacional 20 de noviembre Ciudad de, Mexico
}

\begin{abstract}
Background: Dysmenorrhea is a diseases affecting about $45 \%$ of menstruating women (approximately between 45 to $95 \%$ of females) during the time of menses and causing a reduction of the quality of life.

Objective: To reduce the symptoms of dysmenorrhea using a natural Physiological Mosdulator (A 28) consisting of low dosages of calcium salts, Vitamin D, bioflavonoids, lycopene, and astaxanthin.

Material and methods: Forty patients with severe dysmenorrhea were analyzed during two menstrual cycles: the first as baseline following a run-inn period, and the second during the treatment with A28. A simple VAS scale scoring the daily discomfort (from $0=$ no discomfort to $6=$ maximum discomfort) was used to measure the severity of the symptoms. The total score of first 3 days following the start of menses was calculated.The use of pain rescue cps during the two period was compared.
\end{abstract}

Results: Thirty-eight cases completed the experience. Before treatment, the mean of total scores was $8.1 \pm 2.40$, while after A28 it was reduced to $1.7 \pm 1.39$ (U Mann Whitney $\mathrm{p}<0.01$ ). The mean of pain rescue cps used was respectively $6.1 \pm 1.21$ and $0.5 \pm 1.15$ before and after the A28 treatment $(\mathrm{p}<0.01)$. No side effects were reported.

Conclusion: The use ofa combination of Physiological Modulators effectively decreased the daily discomfort due to dysmenorrhea.

Keywords: Dysmenorrhea, Physiological modulators, Daily discomfort

\section{Introduction}

Dysmenorrhea is a diseases affecting about $45 \%$ of menstruating women (approximately between 45 to $95 \%$ of females) during the time of menses, ${ }^{1}$ causing an extensive personal and public health problem consisting of a high degree of absenteeism and severe economic loss. Recently some author has focused the attention on GABA and CaSRs (calcium sensing receptors): the GABA receptors are spread into the CNS and GI tract with inhibitory activity, ${ }^{2,3}$ while CaSRS are more expressed into the GI. ${ }^{4}$ The GABA receptors have an inhibitory activity which is modulated by estrogens and progestins, and their reduction allows the start of menses. At the same time, the hormonal shortage give rise to pain and GI hypermotility, the last being controlled by the CaSRs inhibitory activity. It may be interesting consider that receptors of any type (e.g. for serotonin, norepinephrine, GABA) are located primarily on the cellular membranes. The membrane functions in general belong to the oxidative condition of the membrane itself, and the receptor is maintained in place with the normal function depending upon the membrane structure around and within the receptor. The membrane around and within the receptor (rafts) can have a differential sensitivity to the oxidative stress (OS) depending upon the quantity of dou-

\begin{tabular}{|l|l|}
\hline Quick Response Code: & *Corresponding author: Umberto Cornelli, Piazza Novelli 5 20129 Milan, Italy \\
Received: 07 November, 2020 & Published: 26 November, 2020 \\
& Citation: Belcaro G, Cornelli U, Hernández SJR. Treatment of Dysmenorrhea with Physiologi- \\
cal Modulators (A28): A Registry Study. Pregn Womens Health Care Int J. 2020;1(1):1-4. D0I: \\
10.53902/PWHCIJ.2021.01.000501
\end{tabular}


ble bonds in the lipids constituting the phospholipids (PL) and the antioxidant reserve available in the cellular system. ${ }^{5}$ Lipids rafts, consisting of cholesterol/sfingolipids microdomains are involved in protein traffic, formation of signaling complexes and are abundantly represented in several postsynaptic dendrites. ${ }^{6}$ This means that a neuroamine receptor (e.g. for serotonin, dopamine) may be more sensible to the oxidation than an estrogenic receptor or vice versa. The consequence of this is that even a mild oxidation in absence of an adequate antioxidant capacity can trigger the dysfunction of some receptors only, whereas a massive oxidation generate a complete dysregulation of all the receptors. In any case, the oxidative stress tends to be an explosive process, and even a mild oxidation starting in one point/area of the cellular membrane may be spread out rapidly involving all the proximal areas. This means that is possible to stop the explosive process just limiting the membrane oxidation, and the relative clinical symptoms will not emerge. These last aspects make clear that OS may compromise directly (receptor per se) or indirectly (rafts oxidation) the neuronal firing, and inhibitory neurons can be more sensible than stimulating neurons, due the higher number of cysteine loops. The aim of this investigation was to analyze the activity of a Physiological Modulators Formula (A28) to control the daily discomfort due to dysmenorrhea symptoms. A28 is a combination of citrus flavonoids to control oxidative stress (OS), calcium salts to modulate pain an motility in the gut, Vitamin D to increase intestinal the calcium availability ${ }^{7}$, astaxanthin to reduce the OS in the brain, ${ }^{8}$ and lycopene to quench the oxidation in lymphocytes. ${ }^{9}$

\section{Material and methods}

The investigation was conducted in women suffering from dysmenorrhea since at least 6 months. They were following a standard management (SM) as usual in the epidemiology center of San Valentino (PE-Italy), ${ }^{10}$ consisting of food intake (mild diet, e.g. limiting carbohydrates, alcohol) and life style modifications (physical training) aimed to reduce the symptoms.

\section{Admission criteria}

Forty women between 19 and 40 years were admitted presenting somatic and behavioral symptoms of dysmenorrhea causing daily discomfort. They were already instructed on how to fill up the daily questionnaire (see later) in the first 3 days of menstruations. The data available for these cases consisted in at least three measures taken using a VAS (Visual Analogue Scale as reported in Table 1) in a the period of 6 months before the study (considered as run-inn period).Those women reporting similar discomfort in the three measures were accepted. The number of cps of any pain killer intake was also measured.

Table 1: Questionnaire for daily discomfort

\begin{tabular}{|c|c|c|}
\hline \multirow{2}{*}{ Day } & Score & Pain rescue \\
\cline { 2 - 3 } & $\mathbf{0 - 6}$ & cps \\
\hline 1 & & \\
\hline 2 & & \\
\hline 3 & & \\
\hline Total & & \\
\hline
\end{tabular}

\section{The dyscomfort was scored between 0 to 6 as follows:}

Score 0 = No discomfort; 1 = Mild (noticeable but not troublesome; $2=$ Moderate (with no interference with normal activities); 3= Moderate (with some interference with normal activities): 4= Moderate (with consistent interference with normal activities); 5 = Severe (need to treated with pain rescue); 6 = Severe not resolved with pain rescue treatment. The subjects were filling up a daily questionnaire (Table 1) reported in a small clinical record form (CRF) and consisting of three evaluations.

\section{Exclusion criteria}

More than 2 points of difference between the three run-inn measures of the daily discomfort, no matter about analgesics/antispasmodics drugs (pain rescue) intake. Women with any chronic diseases were excluded. Women under oral contraceptive treatment were not excluded provided that the treatment was identical for at least 6 months.

\section{Training}

The evaluations in the first day of the appearance of menstruation in the run-inn phase and after treatment were done by the investigators together with the participants. The evaluations of the other two days were done by the participant. The data of each subject were collected in the same CRF.

\section{Treatments}

The treatment consisted of a formula (A28 cps) containing calcium salts (in the form of lactate and carbonate, in total $100.5 \mathrm{mg}$ ), Vitamin D (1mg as vitamin D3), citrus flavonoids (13mg), lycopene $(0.4 \mathrm{mg})$ and astaxanthin $(0.1 \mathrm{mg})$. The dosages have been established according to the concept of Physiological Modulation which is based upon the combination of low dosages of natural components. ${ }^{11,12}$

The treatment consisted of $2 \mathrm{cps}$ of the product just before the expected day of menstruation, followed by other $2 \mathrm{cps}$ at the start of menstruation, and in case of incomplete control of the discomfort, other 2cps could be taken 6 hours, 12 hours, and 24 hours later. A maximum of $10 \mathrm{cps}$ was allowed in the period. In case the treatment was ineffective or minimally effective, the subjects were allowed to use the usual pain killer, and were asked to report the treatment in the questionnaire. The type of analgesics/antispasmodics was free. No records were taken about the trade mark of these products.

A box containing $10 \mathrm{cps}$ od A28 was given to each participants.

\section{Main variables}

The main variable was the sum of the daily scores. The use of pain rescue was considered as an ancillary variable. The data of all the CRFs were collected for the statistical analysis.

\section{Duration of the experience}

All the subjects were already within the registry for dysmenorrhea and admitted for the period of 3 days measurement only. The evaluation were conducted within the month of February 2020. 


\section{Ethical committee}

The experience was approved by the IAPS (International Agency for Pharma Standards) in January 2020.

All the subjects were instructed about the type of treatment, and signed the informed consent.

\section{Compliance}

The compliance was consisting of the counting of residual cps of A28 box. The quantity of pain rescue intake was not part of the compliance.

\section{Statistical Analysis}

In previous studies using the same VAS, for an average of $7 \pm 2.5$ and difference of 2 points, a number of 12 subjects was sufficient to obtain a power of $0.8(\alpha 0.05 ; 1-\beta 0.8)$. In the present study 40 subjects were tested, considering the possibility of $30 \%$ drop out. The number of cases is more than what is necessary to determine significant differences up to 1 point. Average values and dispersion measures were calculated to compare the data obtained before and after the treatment with A28. The differences between the baseline and after treatment scores were tested using the Test U (MannWhitney). The JMP15 Pro of SAS Institute (2020) was used for the calculations.

\section{Results}

Among the 40 enrolled cases 38 cases completed the study.Two drop out were due to logistic reasons 2.

The general characteristics of subjects are summarized in Table

Table 4: Discomfort scores averages, use of pain rescue and A28cps: values at baseline and after A28 treatment (mean and SD) of 38 cases

\begin{tabular}{|c|c|c|c|c|c|c|}
\hline \multicolumn{3}{|c|}{ Baseline } & A28 & \multirow{2}{*}{ Score 0-6 } & \multirow{2}{*}{ Pain rescue cps } & \multirow{2}{*}{$\begin{array}{c}\text { A28 } \\
\text { cps }\end{array}$} \\
\hline Day & Score 0-6 & Pain rescue cps & Day & & & \\
\hline 1 & $4.2 \pm 1.18$ & $2.2 \pm 0.68$ & 1 & $1.1 \pm 0.91 ¥$ & $0.4 \pm 0.78 ¥$ & $4.3 \pm 1.15$ \\
\hline 2 & $2.8 \pm 0.90$ & $2.1 \pm 0.64$ & 2 & $0.4 \pm 0.48 ¥$ & $0.1 \pm 0.32 ¥$ & $1.8 \pm 1.03$ \\
\hline 3 & $1.2 \pm 0.90$ & $1.8 \pm 0.67$ & 3 & $0.3 \pm 0.55 ¥$ & $0.1 \pm 0.32 \ngtr$ & $0.8 \pm 0.99$ \\
\hline Total & $8.1 \pm 2.40$ & $6.1 \pm 1.70$ & & $1.7 \pm 1.39 Y$ & $0.5 \pm 1.15 \nvdash$ & $6.9 \pm 2.26$ \\
\hline
\end{tabular}

$\mathrm{Y}=\mathrm{U}$ Mann-Whitney test before Vs after the use of A28 $\mathrm{p}<0.01$

The main observations that can be drawn are the following:

A. The run-inn period and the baseline values were almost identical for discomfort scores and pain rescue intake (U Mann Whitney $\mathrm{p}>0.05$ )

B. The total discomfort scoring following the treatment was significantly reduced (U Mann Whitney test $\mathrm{p}<0.01$ ) by A28 treatment accounting for an average reduction of $79 \%$ (range 76-87\%)

C. The use of pain rescue cps compared to the baseline period was reduced of about $92 \%$ (range 82-95\%)

D. The average total number of A28 cps in the three-day period was about $7 \mathrm{cps}$ (range 4-10 cps).
Table 2: General characteristics of the subjects: mean values and SD

\begin{tabular}{|c|c|c|}
\hline Variable & Mean & SD \\
\hline Age [years] & 29.3 & 8.19 \\
\hline Age of menarche [years] & 13.1 & 3.95 \\
\hline Duration of menstruation [days] & 3.5 & 0.91 \\
\hline & Frequency & \\
\hline School University degree/total & $4 / 38$ & \\
\hline School Bachelor/total & $7 / 38$ & \\
\hline Activity: professional/total & $35 / 38$ & \\
\hline Activity: house wife/total & $5 / 38$ & \\
\hline Activity: still medical student/total & $2 / 38$ & \\
\hline Smoking/total & $5 / 38$ & \\
\hline Concomitant therapy: oral contraceptive & $36 / 38$ & \\
\hline Concomitant therapy; other & $0 / 38$ & \\
\hline Previous therapy for dysmenorrhea & $38 / 38$ & \\
\hline
\end{tabular}

The level of schooling was quite high since most of the patients were medical professional. The therapy compliance was excellent and no adverse reaction were reported. The total scoring averages are summarized in Tables 3\&4.

Table 3: Run-inn period: discomfort scores average, and use of analgesics/antispasmodic (pain rescue) in the three last measures

\begin{tabular}{|c|c|c|}
\hline \multicolumn{3}{|c|}{ Baseline (mean of $\mathbf{3}$ determinations) } \\
\hline Day & Score $\mathbf{0}-\mathbf{6}$ & Pain rescue cps \\
\hline 1 & $4.2 \pm 1.13$ & $2.2 \pm 0.71$ \\
\hline 2 & $2.9 \pm 0.91$ & $2.1 \pm 0.55$ \\
\hline 3 & $1.2 \pm 0.90$ & $1.7 \pm 0.77$ \\
\hline Total & $8.2 \pm 2.41$ & $5.9 \pm 1.69$ \\
\hline
\end{tabular}


from the analysis of the results. In terms of dosages, considering an average consumption of A28 at 4cps/day, the total amount of the ingredients/day was: $1.25 \mathrm{mg}$ of Vit D (40 IU); $402 \mathrm{mg}$ of Ca, $1.6 \mathrm{mg}$ lycopene, $0.4 \mathrm{mg}$ of astaxanthin, and $52 \mathrm{mg}$ of bioflavonoids. These amounts are lower than the usual quantities available on the common market as food supplements, but their pharmacological effects can be considered at least summative. The hypothesis driving the study was that GABA receptors and CaSRs are not sufficiently activated during the hormonal imbalance driving menses, and the presence of OS impairs the receptors system both in the CNS and in the enteric nervous system (ENS).The results obtained seem to confirm this hypothesis.

A previous study on premenstrual syndrome ${ }^{13}$ was showing the activity of A28 in both behavioral and somatic symptoms following a short term treatment (unfortunately this publication contains many mistakes despite the authors corrections, but the results in terms of \% reduction of the symptoms are correct).

The activity on resetting GABA receptors with flavonoids has been already described. ${ }^{14,15}$ The limited absorption of these compounds ${ }^{16}$ apparently may not allow to reach a sufficient concentration in the brain. However, the presence of enteric and enterohepatic recycling increases the possible contact with target tissues and improves the bioavailability. This does not mean that they can cross the blood brain barrier (BBB) and one may not conclude a possible role on the GABA receptors of the brain. However, they have impact on the ENS receptors and can interrupt the cross stimulation between ENS and CNS.The astaxantin, one of the few antioxidants crossing the blood brain barrier, is present in the formulation and allows to protect the brain tissue from oxidation, despite the low dosage that has been administered. CaSRs modulation is considered important in the $\mathrm{GI},{ }^{17}$ and the administration of Ca may avoid the dysregulation of contractions among the different part of the GI which is one of the causes of colic pain. The low amount of Ca to be administered to restore the CaSRs is also important, since dosages around $1 \mathrm{~g}$ /day with vitamin D about 400 UI was shown to increase the incidence of kidney stones in community- dwelling adults. ${ }^{18}$ Despite the lower age of the subjects enrolled in the present experience, the maximum Ca intake was limited to about $600 \mathrm{mg}$ (in the case of 6cps/day). Lycopene is known to modulate lymphocyte reactivity, ${ }^{19}$ and astaxanthin is well documented for its capability to cross the blood-brain barrier and counteract oxidative stress causing neurological diseases..$^{20}$ The combination of all these effects can be very helpful in reducing symptoms causing the daily discomfort. $^{21}$

\section{Conclusion}

A28 was shown very effective in reducing symptoms of dysmenorrhea and sufficient to improve the daily discomfort without using, or consistently limiting (about 92\%), the use of analgesics/ antispasmodics drugs.

\section{Acknowledgments}

Modigal S. deR.L de C.V-Mexico City was giving A28 free of charge. UC conceived the trial and wrote the text, GB was executing the trial, HSJR was controlling all the records forms.

\section{Funding}

None.

\section{Conflicts of Interest}

No conflict of interest for any of the authors.

\section{References}

1. Iacovides S, Avidon I, Baker FC. What we know about primary dysmenorrhea today: a critical review. Hum Rep Update. 2015;21(6):762778.

2. Froesti W. GABA receptors. Biotrend Rev. 2011;7:1.

3. Sigel E, Steinman ME. Structure, function, and modulation of GABA $_{A}$ receptors. J Biol Chem. 2012;287(48):40224-40231.

4. Alfadda TI, Saleh AMA, Houillier P, et al. Calcium-sensing receptor 20 years later. Am J Cell Physiol. 2014;307(3):C221-C231.

5. Nothdurfer C, Tanasic S, Di Benedetto, B et al. Lipid raft integrity affects GABA $_{A}$ receptor, but not NMDA receptor modulation by psychopharmacological compounds. Int J Neuropsychopharmacology. 2013;16:1361-1371.

6. Hering H, Lin CC, Sheng M. Lipid rafts in the maintenance, dendritic spines, and surface AMPA receptor stability. J Neurosci. 2003;23(8):3267-3271.

7. Giraldi G, Fioravanti A, de Luca D’Alessandro E, et al. Investigation of effects of vitamin D and calcium on intestinal motility: in vitro tests and implications for clinical treatment. Acta Pharm. 2015;65(3):343-349.

8. Grimmig B, Kim S, Nash K, et al. Neuroprotective mechanism of asthaxantin: a potential therapeutic role in preserving cognitive function in age and neurodegeneration. Gero Science. 2017;39(1):19-32.

9. Müller L, Caris Veirat C, Lowe G, et al. Lycopene and its antioxidant role in the prevention of cardiovascular diseases- A critical review. Crit Rev Food Sci Nutr. 2016;56(11):1868-1979.

10. Cesarone MR, Belcaro G, Nicolaides AN, et al. San Valentino Epidemiologic vascular project. Angiology. 2000;51(8):565-568.

11. Finco A, Belcaro G, Cesarone MR. Assessment of the activity of an oral contraceptive on the levels of oxidative stress and changes in oxidative stress after co-treatment with two different types of physiological modulators with antioxidant action. Contraception. 2011;84(4):418422.

12. Hanrahan JR, Chebib M, Johnston GA. Interaction of flavonoids with ionotropic GABA receptors. Adv Pharmacol. 2015;72:189-200.

13. Johnston GA. Flavonoid nutraceuticals and ionotropic receptors for the inhibitory neurotransmitter GABA. Neurochem Int. 2015;89:120-125.

14. Cornelli U Hernández Santos JR, Belcaro G. Premenstrual Syndrome (PMS) treatment with Physiological Modulators. Gyn \& Obst. 2020;10(4):1:7.

15. Hanranan JR, Chebib M, Johnston GAR. Interaction of flavonoids with ionotropic GABA receptors. Adv Pharmacol. 2015;72:189-200.

16. Johnston GAR. Flavonoid nutraceuticals and ionotropic receptors for the inhibitory neurotransmitter GABA. Neurochem Int. 2015;89:120-125.

17. Gonzales GB, Smagghe G, Grootaert C, et al. Flavonoid interaction during digestion, absorption, distribution and metabolism: a sequential structure-activity/property relationship-based approach in the study of bioavailability and bioactivity. Drug Metab Rev. 2015;47(2):175-190.

18. Thakker RV. Calcium-sensing receptor: role in health and disease. Ind J Endocrinol Metab. 2012;16(Suppl 2):S213-S216.

19. Grossman DC, Curry SJ, Owens DK, et al. Vitamin D, calcium, or combined supplementation for the primary prevention of fractures in communitydwelling adults: US Preventive Service Task Force Recommendation Statement. JAMA. 2018;319(15):1592-1599.

20. Thies F, Mills LM, Moir S, et al. Cardiovascular benefit of lycopene: fantasy or reality?. Proc Nutr Soc. 2017;76(2):122-129.

21. Galasso C, Orefice I, Pallone P, et al. On the neuroprotective role of astaxanthin: new perspectives? Mar Drug. 2018;16(8):247. 